\title{
DESIGN OF FRACTIONAL ORDER PID CONTROLLER BASED PARTICLE SWARM
}

\author{
Abdelelah Kidher Mahmood ${ }^{1}$, Bassam Fadel Mohammed ${ }^{2}$ \\ ${ }^{1}$ Assistant Professor, ${ }^{2}$ M.Sc. Student, College of Engineering, University of Mosul \\ E-mail: Kmabdelelah@yahoo.com, bassam7219@yahoo.com \\ (Received: 6/5/2013; Accepted: 26/11/2013)
}

\begin{abstract}
Fractional order PID (FOPID) controller is a special kind of PID controller whose derivative and integral order are fractional rather than integer which has five parameters to be tuned. This paper presents study of the implementation of tuning method and performance enhancement of the closed loop system by use of the fractional order PID $\left(\mathrm{PI}^{\lambda} \mathrm{D}^{\mu}\right)$ controller utilizing a MATLAB/Simulink. The tuning methods for these type controllers have many mixed tools of the available optimization methods and update artificial optimization methods in the design. In this paper particle swarm optimization has been implemented to design FOPID controller in which the unknown parameters are determined minimizing a given integral of time weighted absolute error (ITAE). The main specification of this paper is that the all five parameters of $\left(\mathrm{PI}^{\lambda} \mathrm{D}^{\mu}\right)$ have been found directly without spreading the steps. It has been shown that the response and performance of the closed loop system with FOPID controller is much better than integer order PID controller for the same system and with better robustness.
\end{abstract}

Keywords: FOPID controller, Particle Swarm.

\section{1- INTRODUCTION}

PID controller is a wide spread, and well known controller which is implemented practically in the most industries and in other applications. As an example for the application of PID controller in industry, slow industrial process can be pointed, low percentage overshoot and small settling time can be obtained by using this controller. In feedback control systems the controller function has ability to eliminate steady state offsets through derivative action. The derivative action in the control loop will improve the damping and therefore accelerating the transient response. By generalizing the derivative and integer orders, from the integer field to non-integer numbers, the fractional order PID control is obtained ${ }^{(1)}$. The performance of the PID controller can be improved by making the use of fractional order derivatives and integrals. This flexibility can be helps the design for more robust system. The 
most important advantages of the $\mathrm{PI}^{\lambda} \mathrm{D}^{\mu}$ controller is the better control of dynamical systems and less sensitive to changes of parameters of a control system ${ }^{(2)}$. Before using the fractional order controller in design an introduction to the fractional calculus is required. The first time, calculus generation to fractional, was proposed Leibniz and Hopital for the first time after words, the systematic studies in this field by many researchers such as Liouville (1832), Holmgren (1864) and Riemann (1953) were performed ${ }^{(1)}$ Due to Widespread usage of PID controller in industries and product manufactures so researchers always motivated to look for abettor and suitable design method or alternative controller ${ }^{(3)}$. For example, the fractional order algorithm for the control of dynamic systems has been introduced by utilization of CRONE (French abbreviation for Command Robusted'Ordre Non Entier), over the PID controller, which has been demonstrated by Oustaloup ${ }^{(4)}$. Podlubny has proposed a generalization of the PID controller as $\mathrm{PI}^{\lambda} \mathrm{D}^{\mu}$ controller which is known as fractional order PID controller, where $\lambda$ is the non-integer order of integrator and $\mu$ is the non-integer order of the differentiator term. He also demonstrated that the $\mathrm{PI}^{\lambda} \mathrm{D}^{\mu}$ controller has better response than classical PID controller ${ }^{(5)}$. Frequency domain approaches of $\mathrm{PI}^{\lambda} \mathrm{D}^{\mu}$ controller are studied in ${ }^{(6)}$. Also many valuable studies have been done for fractional order controllers and their implementations in two discretization methods. The first scheme is a direct recursive discretization of the Tustin operator. The second one is a direct discretization method using the Al-Alaoui operator via continued fraction expansion (CFE) ${ }^{(7)}$. Crucial importance of tuning of the controllers cannot be underestimated. Thus, many tuning techniques for obtaining the parameters of the controllers were introduced during last few decades. Tuning methods of $\mathrm{PI}^{\lambda} \mathrm{D}^{\mu}$ controllers are recent research subject. Most of the researchers oriented to the classical optimization and intelligent methods ${ }^{(8)}$.Some tuning rules for robustness to plant uncertainty for $\mathrm{PI}^{\lambda}$ controller are given in ${ }^{(9)}$.However in order to achieve better results, there are still needs for new methods to obtain the parameters of $\mathrm{PI}^{\lambda} \mathrm{D}^{\mu}$ controllers.

In this paper the Particle Swarm Optimization (PSO) algorithm has been used to tune the parameter of $\mathrm{PI}^{\lambda} \mathrm{D}^{\mu}$ controller in order to get an optimum time domain specifications in which integral of time weighted absolute error (ITAE) has been minimized and the results compared with conventional PID and with some other methods like the proposed method by (Vineet Shekher, Pankaj Rai and Om Prakash) ${ }^{(1)}$, in which the parameters of $\mathrm{PI}^{\lambda} \mathrm{D}^{\mu}$ controller has been obtained in three steps where Zeigler and Nichols method to find proportional Kp, integral Ki parameters, Astrom - Hagglund method to find derivative parameter $\mathrm{Kd}$ and the remained parameter $\lambda$ and $\mu$ found by optimization toolbox of the MATLAB " fsolve". While in our method the optimization method, the five parameters found directly by utilizing PSO algorithm. 


\section{DESIGN OF FRACTIONAL ORDER PID CONTROLLER BASED PARTICLE SWARM}

\section{2- MATHEMATICAL BACKGROUND}

Fractional calculus is a generalization of integration and differentiation to non-integer order fundamental operator ${ }_{a} D^{r}$, where $a$ and $t$ are the limits of the operation and $r \in R$. The continuous Integra-differential operator is defined as:

$$
{ }_{a} D^{r}{ }_{t}= \begin{cases}\frac{d^{r}}{d t^{r}} & : r>0, \\ 1 & : r=0, \\ \int_{a}^{t}(d \tau)^{-r} & : r<0 .\end{cases}
$$

The three equivalent definitions most frequently used for the general fractional differ integral are the Grünwald-Letnikov (GL) definition, the Riemann-Liouville (RL) and the Caputo definition. The GL definition is given by:

$$
{ }_{a} D_{t}^{r} f(t)=\lim _{h \rightarrow 0} h^{-r} \sum_{j=0}^{\left[\frac{t-a}{h}\right]}(-1)^{j}\left(\begin{array}{l}
r \\
j
\end{array}\right) f(t-j h)
$$

where [.] means the integer part. The RL definition is given as:

$$
{ }_{a} D_{t}^{r} f(t)=\frac{1}{\Gamma(n-r)} \frac{d^{n}}{d t^{n}} \int_{a}^{t} \frac{f(\tau)}{(t-\tau)^{r-n+1}} d \tau
$$

for $(n-1<r<n)$ and where $\Gamma$ (.) is the Gamma function. The Caputo definition can be written as:

$$
{ }_{a} D_{t}^{r} f(t)=\frac{1}{\Gamma(n-r)} \int_{a}^{t} \frac{f^{(n)}(\tau)}{(t-\tau)^{r-n+1}} d \tau
$$

for $(n-1<r<n)$. The initial conditions for the fractional order differential equations with the Caputo derivatives are in the same form as for the integer-order differential equations. In the above definition, $\Gamma(m)$ is the factorial function, defined for positive real $m$, by the following expression:

$$
\Gamma(m)=\int_{0}^{\infty} e^{-u} u^{m-1} d u
$$

for which, when $\mathrm{m}$ is an integer, it holds that:

$$
\Gamma(m+1)=m \text { ! }
$$

The definition of fractional derivative easily derives by taking an $n$ order derivative ( $n$ suitable integer) of a $m$ order integral ( $m$ suitable non integer) to obtain an $n-m=q$ order one:

$$
\frac{d^{q} f(t)}{d t^{q}}=\frac{d^{n-m} f(t)}{d t^{n-m}}=\frac{1}{\Gamma(m) d t^{n}} \frac{d^{n}}{d t^{n}} \int_{0}^{t}(t-y)^{m-1} f(y) d y
$$

It must be noted that for $q=1(n=2, m=1)$, (7) becomes the canonical first order derivative. 
Laplace transform of non-integer order derivatives is necessary for an optimal study. Fortunately, not very big differences can be found with respect to the classical case, confirming the utility of this mathematical tool even for fractional systems. Inverse Laplace transformation is also useful for time domain representation of systems for which only the frequency response is known. The most general formula is the following:

$$
L\left\{\frac{d^{m} f(t)}{d t^{m}}\right\}=s^{m} L\{f(t)\}-\sum_{k=0}^{n-1} s^{k}\left[\frac{d^{m-1-k} f(t)}{d t^{m-1-k}}\right] \ldots \ldots \ldots
$$

where $n$ is an integer such that $n-1<m<n$.

The above expression becomes very simple if all the derivatives are zero ${ }^{(10)}$ :

$$
L\left\{\frac{d^{m} f(t)}{d t^{m}}\right\}=s^{m} L\{f(t)\}
$$

A fractional order system is that system described by the following fractional order differential equation:

$$
\begin{aligned}
& { }_{a n} D^{\alpha n} f(x)+{ }_{a n-1} D^{\alpha n-1} f(x)+{ }_{a n-2} D^{\alpha n-2} f(x)+\cdot \cdot \cdot \\
& ={ }_{b n} D^{\beta n} f(x)+{ }_{b n-1} D^{\beta n-1} f(x)+{ }_{b n-2} D^{\beta n-2} f(x)+\cdot \cdot \cdot
\end{aligned}
$$

where $D^{\alpha n}={ }_{0} D_{t}^{\alpha n}$, is called the fractional derivative of order $\alpha n$ with respect to variable $t$ and with the starting point $t=0,{ }^{(11)}$.

\section{3- FRACTIONAL ORDER PID (FOPID) CONTROLLER}

The integro-differential equation defining the control action of a fractional order PID controller is given by:

$$
u(t)=K_{p} e(t)+K_{i} D^{-\lambda} e(t)+K_{d} D^{\mu} e(t)
$$

Applying Laplace transform to this equation with null initial conditions, the transfer function of the controller can be expressed by:

$$
C_{\mathrm{f}}(s)=K_{\mathrm{p}}+K_{\mathrm{i}} s^{-\lambda}+K_{\mathrm{d}} s^{\mu}=\mathrm{K} \frac{\left(\frac{s}{w f}\right)^{\lambda+\mu}+\frac{s \delta_{f} s^{\lambda}}{w f}+1}{s^{\lambda}}
$$

In a graphical way, the control possibilities using a fractional-order PID controller are shown in Figure (1), extending the four control points of the classical PID to the range of control points of the quarter-plane defined by selecting the values of $\lambda$ and $\mu^{(12)}$.

\section{4- PARTICLE SWARM OPTIMIZATION (PSO) AN OVERVIEW}

The goal of particle swarm optimization is to solve the computationally hard optimization problems, where it is a robust optimization technique based on the movement and intelligence of swarms and applied successfully to a wide variety of search and 
optimization problems. It was inspired from the swarms in nature such as swarms of birds, fish, etc. The PSO was developed in 1995 by James Kennedy and Russ Eberhart. The algorithm adopted uses a set of particles flying over a search space to locate a global optimum, where a swarm of n particles communicate either directly or indirectly with one another using search directions, in each iteration of PSO, each particle updates its position based on three components, by determines its velocity using, previous velocity, best previous position, and the best previous position of its neighborhood. Figure (2) illustrate the flow chart of PSO algorithm. The basic concept of PSO lies in accelerating each particle toward the best position found by it so far (pbest) and the global best position (gbest) obtained so far by any particle, with a random weighted acceleration at each time step, this is done by the equations (13) and (14):

$$
\begin{gathered}
\mathrm{V}_{\mathrm{t}+1}=\mathrm{W}^{*} \mathrm{~V}_{\mathrm{t}}+\mathrm{C}_{1} * \text { rand }(0,1)^{*}\left(\text { pbest }-\mathrm{X}_{\mathrm{t}}\right)+\mathrm{C}_{2} * \text { rand }(0,1) *\left(\text { gbest }-\mathrm{X}_{\mathrm{t}}\right) \ldots \ldots \\
\mathrm{X}_{\mathrm{t}+1}=\mathrm{X}_{\mathrm{t}}+\mathrm{V}_{\mathrm{t}+1} \ldots \ldots \ldots
\end{gathered}
$$

Where: gbest $=$ Global Best Position .

Pbest $=$ Self Best Position .

$\mathrm{C}_{1}$ and $\mathrm{C}_{2}=$ Acceleration Coefficients.

$\mathrm{W}=$ Inertial Weight.

$\mathrm{Vt}=$ Velocity.

$\mathrm{X}_{\mathrm{t}}=$ Particle.

Once the particle computes the new $\mathrm{X}_{\mathrm{t}}$ it then evaluates its new location. If fitness (X t) is better than fitness (pbest), then pbest $=X_{t}$ and fitness (pbest) $=$ fitness $\left(X_{t}\right)$, in the end of iteration the fitness $($ gbest $)=$ the better fitness (pbest) and gbest $=$ pbest ${ }^{(13)}$.

\section{5- COMPUTATION OF PI ${ }^{\lambda} D^{\mu}$ CONTROLLER PARAMETER}

The negative unity feedback control system with MATLAB simulation which is shown in Figure(3), where the fractional order PID (FOPID) controller $\mathrm{G}_{\mathrm{c}}(\mathrm{s})$ implemented by using fractional control toolbox ${ }^{(14)}$, the integral of time weighted absolute error (ITAE) as objective function (fitness function) and the plant $\mathrm{G}(\mathrm{s})$ were implemented by MATLAB toolbox.

$$
\begin{aligned}
G_{c}(s) & =K_{p}+\frac{K_{i}}{s^{\lambda}}+K_{d} s^{\mu} \ldots \ldots \ldots \\
G(s) & =\frac{1}{\left(s^{3}+3 s^{2}+2 s\right)} \ldots \ldots \ldots \\
\text { IT AE } & =\int_{0}^{\infty} t|e(t)| d t \ldots \ldots \ldots
\end{aligned}
$$


The PSO algorithm method has been implemented as $\mathrm{M}$ file which interconnected to simulink model where the FOPID controller parameters are computed and feed to the GUI of the controller. The optimization performed with this initial parameter, number of particles (30), number of dimensions (5), maximum iteration (50), $\mathrm{C}_{1}=1, \mathrm{C}_{2}=3$, with the objective function (fitness function) (ITAE). The initial values of five parameters of the fractional order PID controller $(\mathrm{Kp}, \mathrm{Ki}, \mathrm{Kd}, \lambda$ and $\mu$ ) will be generate in PSO program and submit in simulation diagram in Figure (3) and running the simulation automatically then compute the objective function (fitness function) (ITAE) and go back with value of (ITAE) to PSO program to improve the value of $(\mathrm{Kp}, \mathrm{Ki}, \mathrm{Kd}, \lambda$ and $\mu)$ and go on, in the end of iteration the five parameters of the fractional order PID controller $(\mathrm{Kp}, \mathrm{Ki}, \mathrm{Kd}, \lambda$ and $\mu$ ) has been obtained directly according to the minimum value of objective function (fitness function) (ITAE). The obtained results shown in the Table (1). Step response of the system in Figure (3) for the FOPID controller tuned by PSO algorithm in Table (1), illustrated in Figure (4). While the results that obtained in the proposed method by authors in ${ }^{(1)}$ for $\lambda$ and $\mu$ and other parameters of the controller for different methods like Zigler-Nichols, Åström-Hägglund and the refsolver optimization method, shown in the Table (2). Step response of the system in Figure (3), for each controller in Table (2) illustrated in Figure (5).

Step response of the system gives valuable information such as Maximum overshoot $\left(\mathrm{M}_{\mathrm{o} . \mathrm{s}} \%\right)$, rise time $\left(\mathrm{T}_{\mathrm{r}}\right)$, peak time $\left(\mathrm{T}_{\mathrm{p}}\right)$ and settling time $\left(\mathrm{T}_{\mathrm{s}}\right)$. It can be observed from the Table (3) that, the PSO algorithm method gives much better time domain performance with respect to the proposed methods in ${ }^{(1)}$, specially for maximum overshoot $\left(\mathrm{M}_{\mathrm{o} . \mathrm{s}} \%\right)$, rise time $\left(\mathrm{T}_{\mathrm{r}}\right)$, peak time $\left(\mathrm{T}_{\mathrm{p}}\right)$ and settling time $\left(\mathrm{T}_{\mathrm{s}}\right)$.

\section{6- ROBUSTNESS TEST OF THE SYSTEM}

The main advantages of the fractional order controller are the robustness of the system whenever a disturbance occurred and in case of the uncertainty in the parameters. The system which has been designed tested by two type of disturbance one is when a load or perturbation was applied on the system. The second when selected parameters are deviated from its original value by $20 \%$. The Figure (6) shown the simulation system for PID and FOPID controller with disturbance putting after the plant, because if the disturbance put between the controller and the plant the system never effect (i.e. the system is very robust), Figure (7) shown that the system for FOPID controller remains stable and very little effect on the time domain performance which means the sensitivity is very much low considering the deviated parameter from is original value, comparing with Figure (8) shown that the $\underline{\text { system for PID controller effect on the time domain performance for the deviated parameter }}$ 
from is original value, Figure (9) shown the system sensitivity for FOPID is very low considering the disturbance effect compared with PID. The Table (4) shown the time domain performance for System FOPID Controller with Disturbance Figure (8-a) is better than the System PID Controller with Disturbance Figure (8-b).

\section{7- CONCLUSION}

In this work the PSO algorithm has been utilized to find the optimal parameters of FOPID controller which minimizing the (ITAE).The major properties of our proposed method, the five parameters $(\mathrm{Kp}, \mathrm{Ki}, \mathrm{Kd}, \lambda$ and $\mu$ ) are found directly without spreading in steps and without need of finding the first three term of the controller. The system with FOPID controller exhibit good time domain response as compared with the integer order PID. Besides the system becomes more robust in which a good rejection of the disturbance and less sensitive to deviation in system parameters.

\section{REFERENCES}

1. V. Shekher, P. Rai and O. Prakash, (2012), "Tuning and Analysis of Fractional Order PID Controller", International Journal of Electronic and Electrical Engineering. ISSN 09742174 Vol. 5, No. 1, pp. 11-21.

2. D. Xue and Y. Q. Chen, (2006), "Fractional Order PID Control of a DC-Motor with Elastic Shaft: a Case Study", IEEE, 1-4244-0210-7/06, pp. 3182-3187.

3. K. Åström and T. Hägglun, (1995), "PID controllers: Theory, Design and Tuning", $2^{\text {nd }}$ Edition, Instrument society of America, No. of Pages 343.

4. A. Oustaloup, F. Levron, B. Mathieu and F. M. Nanot, (2000), "Frequency-Band Complex Non integer Differentiator: Characterization and Synthesis", IEEE Transactions on Circuits and Systems I: Fundamental Theory and Applications, Vol. 47, No. 1, pp. 2539.

5. I. Podlubny, (1999), "Fractional-order systems and $\mathrm{PI}^{\lambda} \mathrm{D}^{\mu}$ controllers", IEEE Transactions on Automatic Control, Vol.44, No. 1, pp. 208-214.

6. B. M. Vinagre, I. Podlubny, L. Dorcak and V. Feliu, (2000), "On fractional PID controllers: A frequency domain approach", IFAC workshop on digital control. Past, present and future of PID control, pp. 53-58.

7. Y. Q. Chen and K. L. Moore, (2002), "Discritization schemes for fractional order Differentiators and integrators", IEEE Transactions on Circuits and Systems I: Fundamental Theory and Applications, Vol. 49, No. 3, pp. 363-367. 
8. C. A. Monje, B. M. Vinagre, V. Feliu and Y.Q. Chen, (2008), "Tuning and auto-tuning of fractional order controllers for industry applications", Control Engineering Practice, Vol. 16, pp.798-812.

9. C. A. Monje, A. J. Calderon, B. M. Vinagre, Y. Q. Chen and V. Feliu., (2004), "On Fractional PI ${ }^{\lambda}$ Controllers: Some Tuning Rules for Robustness to Plant Uncertainties", Nonlinear Dynamics, Vol. 38, pp. 369-381.

10. R. Caponetto, G. Dongola, L. Fortuna and I. Petráš, (2010), "Fractional Order Systems: Modeling and Control Applications", Series A Vol. 72, Singapore, World Scientific Series on Nonlinear Science, No. of Pages 178.

11. D. Baleanu, J. A. T. Machado and A. C. J. Luo, (2012), " Fractional Dynamics and Control", USA, Springer Science + Business Media, No. of Pages 309.

12. C. A. Monje, Y. Q. Chen, B. M. Vinagre, D. Xue and V. Feliu, (2010), "Fractional-order Systems and Controls: Fundamentals and Applications", London, Springer-Verlag London Limited, No. of Pages 414.

13. V. Gazi and K. M. Passino, (2011), "Swarm Stability and Optimization", German, Springer Science + Business Media, No. of Pages 299.

14. D. P. Mata and O. Valério, (2005), "Ninteger V. 2.3 Fractional control toolbox for MatLab", Lisboa: Instituto Superior Técnico da Universidade Técnica de Lisboa, No. of Pages 96. (http://www.mathworks.com/matlabcentral/ file exchange).

Table (1): Parameters of FOPID Controller Obtained by PSO algorithm

\begin{tabular}{|c|c|c|c|c|c|}
\hline \multirow[b]{2}{*}{$\begin{array}{l}\text { Tuning Method } \\
\text { and Controller }\end{array}$} & \multicolumn{5}{|c|}{ Parameters } \\
\hline & $\mathrm{Kp}$ & $\mathrm{Ki}$ & $\mathrm{Kd}$ & $\lambda$ & $\mu$ \\
\hline $\begin{array}{l}\text { PSO Algorithm, } \\
\text { (FOPID) }\end{array}$ & 98.1959 & 0 & 70.9573 & 0 & 1.4497 \\
\hline
\end{tabular}

Table (2): Parameters of PID \& FOPID Controllers Obtained by Different Methods.

\begin{tabular}{|c|c|c|c|c|c|}
\hline \multirow{2}{*}{$\begin{array}{c}\text { Tuning Method } \\
\text { and Controller }\end{array}$} & $\mathrm{Kp}$ & $\mathrm{Ki}$ & $\mathrm{Kd}$ & $\lambda$ & $\mu$ \\
\cline { 2 - 6 } & 3.6 & 1.63 & 1.98 & 1 & 1 \\
\hline $\begin{array}{c}\text { Zigler-Nichols, } \\
\text { (PID) }\end{array}$ & 4.59 & 1.51 & 3.48 & 1 & 1 \\
\hline $\begin{array}{c}\text { Aström-Hägglund, } \\
\text { (PID) }\end{array}$ & 3.6 & 1.63 & 3.75 & 1.39 & 0.79 \\
\hline $\begin{array}{c}\text { Proposed method } \\
\text { in [1], (FOPID) }\end{array}$ & & &
\end{tabular}


DESIGN OF FRACTIONAL ORDER PID CONTROLLER BASED PARTICLE SWARM

Table (3): Step Response Specification of PID \& FOPID Controllers.

\begin{tabular}{|c|c|c|c|c|}
\hline \multirow{2}{*}{$\begin{array}{c}\text { Tuning Method } \\
\text { and Controller }\end{array}$} & $\begin{array}{c}\text { Maximum } \\
\text { overshoot } \\
\left(\mathrm{M}_{\text {o.s }} \%\right)\end{array}$ & $\begin{array}{c}\text { Peak Time } \\
\left(\mathrm{T}_{\mathrm{p}}\right)\end{array}$ & $\begin{array}{c}\text { Rise time } \\
\left(\mathrm{T}_{\mathrm{r}}\right)\end{array}$ & $\begin{array}{c}\text { Settling Time } \\
\left(\mathrm{T}_{\mathrm{s}}\right)\end{array}$ \\
\hline $\begin{array}{c}\text { Zigler-Nichols, } \\
\text { (PID) }\end{array}$ & 73.5 & 1.67 & 3.25 & 12.5 \\
\hline $\begin{array}{c}\text { Asström- } \\
\text { Hägglund, } \\
\text { (PID) }\end{array}$ & 43 & 1.66 & 2.95 & 6.67 \\
\hline $\begin{array}{c}\text { Proposed } \\
\text { method in [1], } \\
\text { (FOPID) }\end{array}$ & 27.9 & 0.96 & 1.74 & 4.65 \\
\hline $\begin{array}{c}\text { PSO Algorithm, } \\
\text { (FOPID) }\end{array}$ & 19.7 & 0.195 & 0.084 & 0.476 \\
\hline
\end{tabular}

Table (4): Step Response Specification of PID \& FOPID Controller with Disturbance.

\begin{tabular}{|c|c|c|c|c|}
\hline \multirow{2}{*}{$\begin{array}{c}\text { System } \\
\begin{array}{c}\text { \&Tuning } \\
\text { Method of } \\
\text { Controller }\end{array}\end{array}$} & $\begin{array}{c}\text { Maximum } \\
\text { overshoot } \\
\left(\mathrm{M}_{\mathrm{o.s}} \%\right)\end{array}$ & $\begin{array}{c}\text { Peak Time } \\
\left(\mathrm{T}_{\mathrm{p}}\right)\end{array}$ & $\begin{array}{c}\text { Rise time } \\
\left(\mathrm{T}_{\mathrm{r}}\right)\end{array}$ & $\begin{array}{c}\text { Settling Time } \\
\left(\mathrm{T}_{\mathrm{s}}\right)\end{array}$ \\
\hline $\begin{array}{c}\text { Aström- } \\
\text { Hägglund, } \\
\text { (PID) }\end{array}$ & 40 & 2 & 0.76 & 11.5 \\
\hline $\begin{array}{c}\text { PSO Algorithm, } \\
\text { (FOPID) }\end{array}$ & 19.7 & 0.23 & 0.091 & 2.38 \\
\hline
\end{tabular}

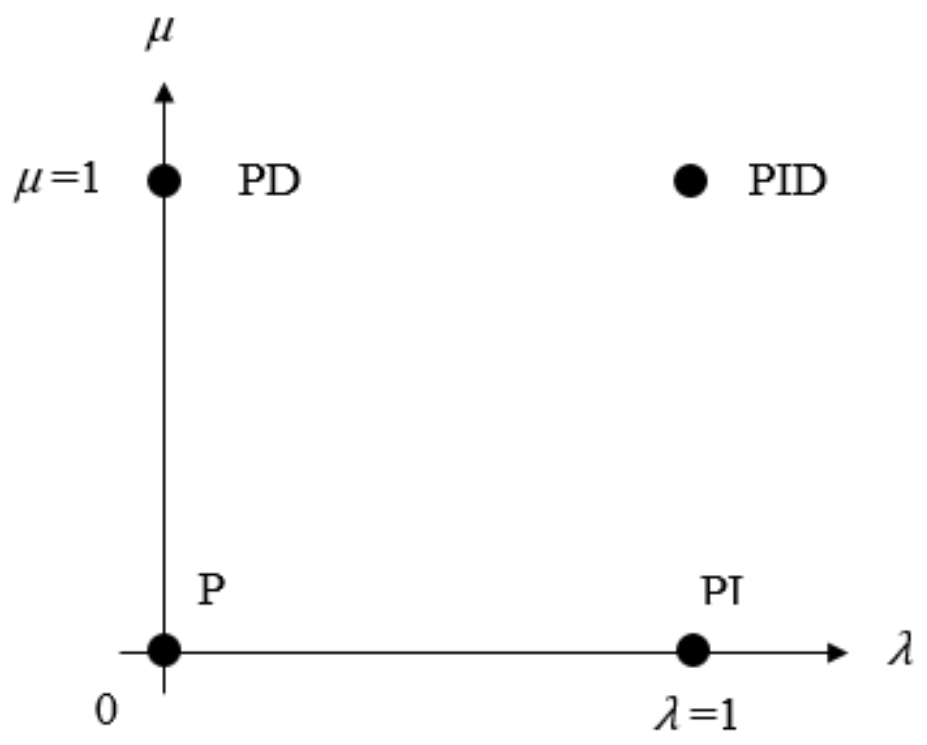

Figure (1): Fractional-order PID vs classical PID. 


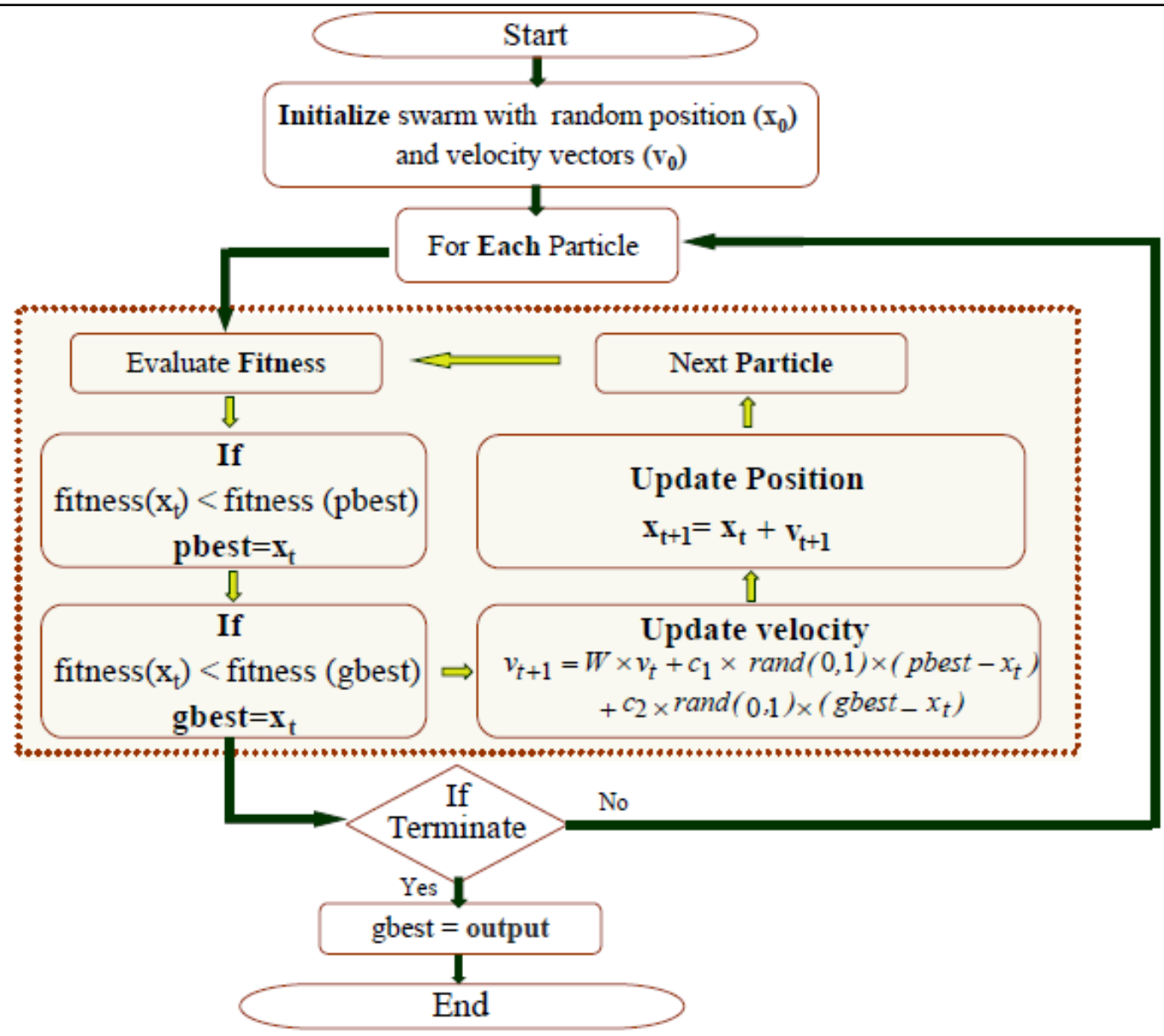

Figure (2): Flow Chart of PSO Algorithm.

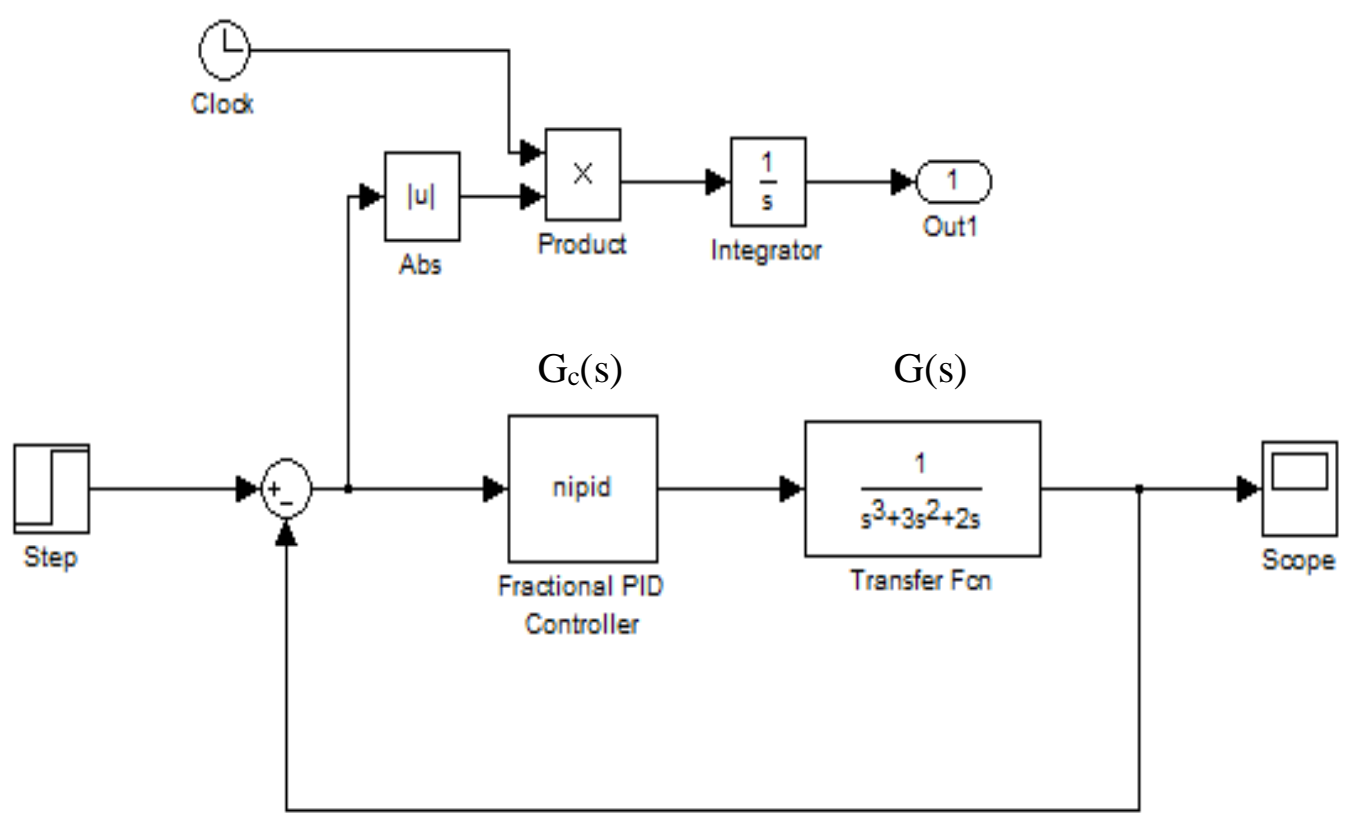

Figure (3): Negative unity feedback FOPID control system. 


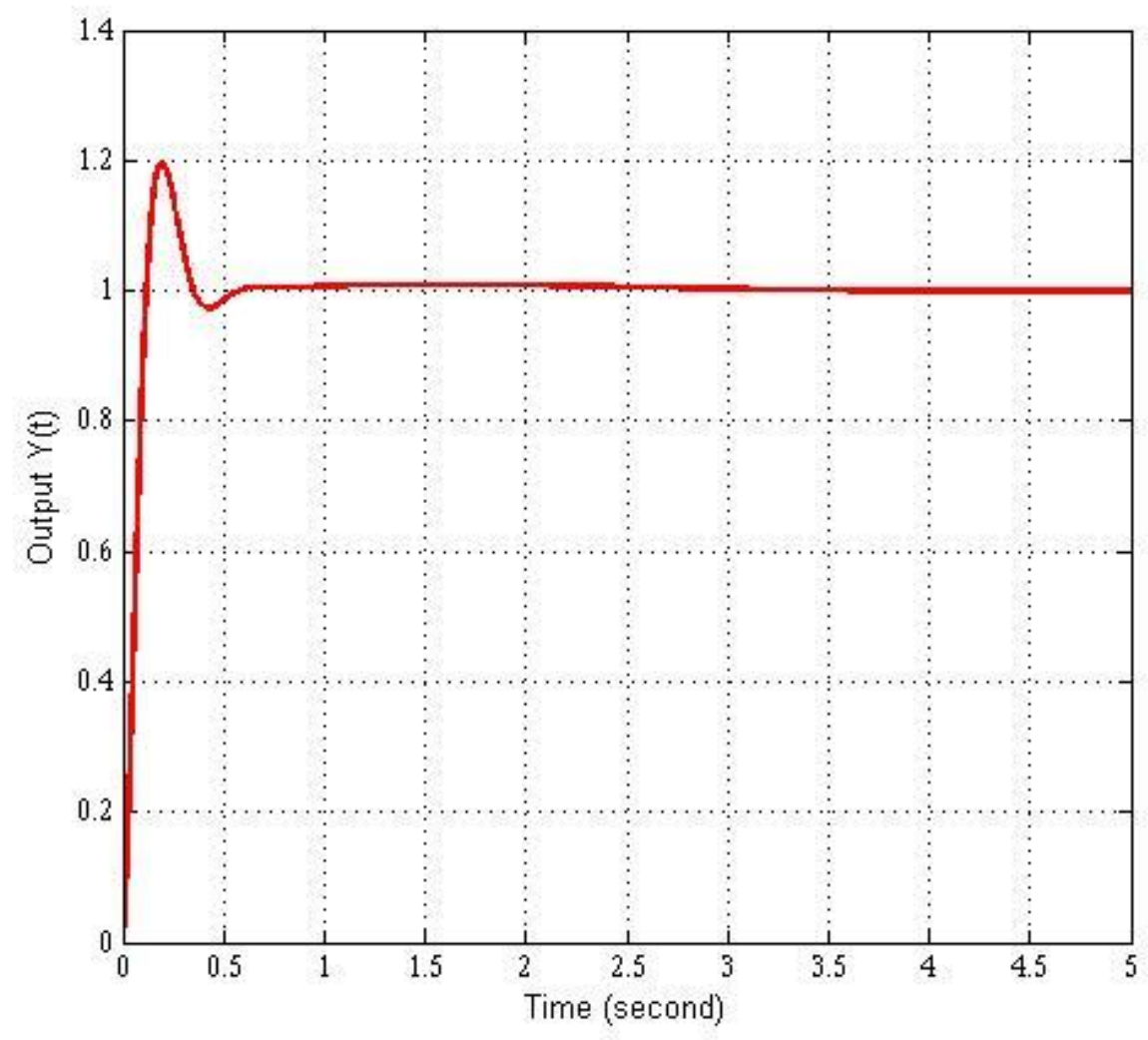

Figure (4): Step response of Negative unity feedback FOPID control system.

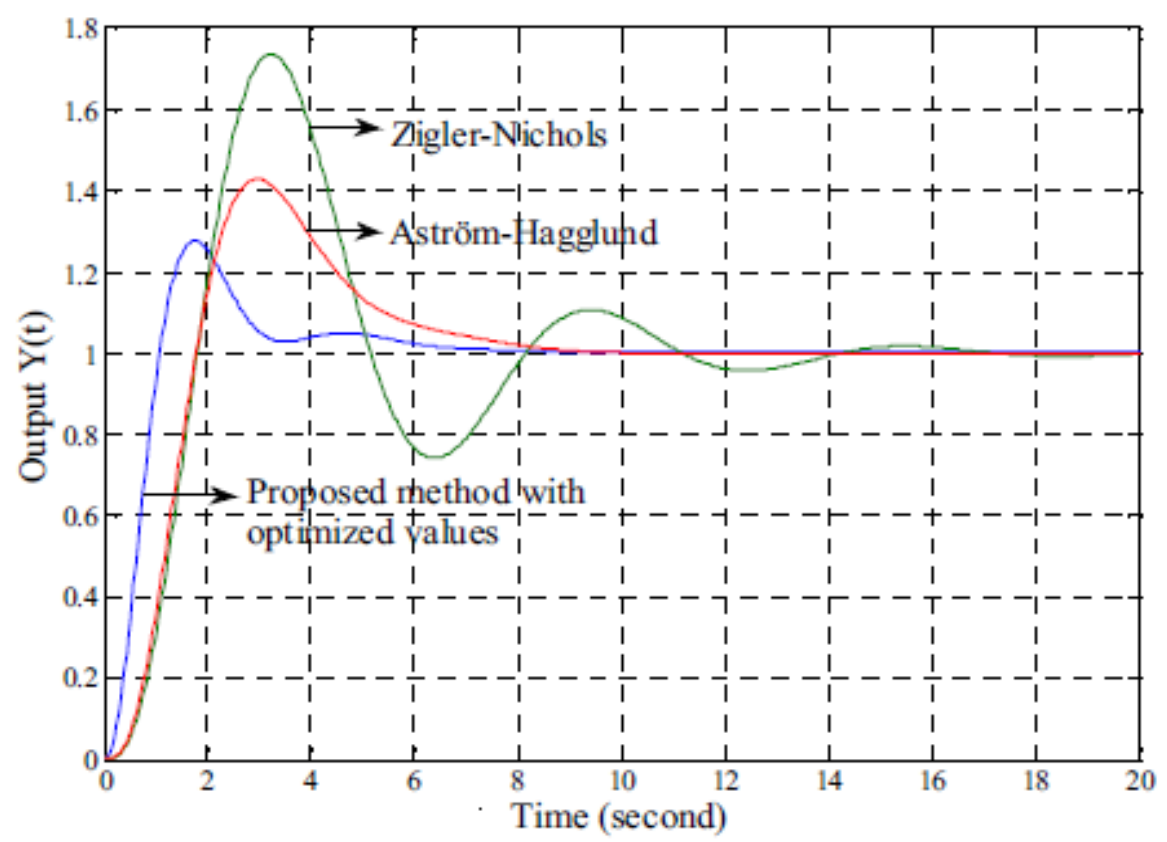

Figure (5): Step response of PID \& FOPID control systems Tuned by Different Methods. 


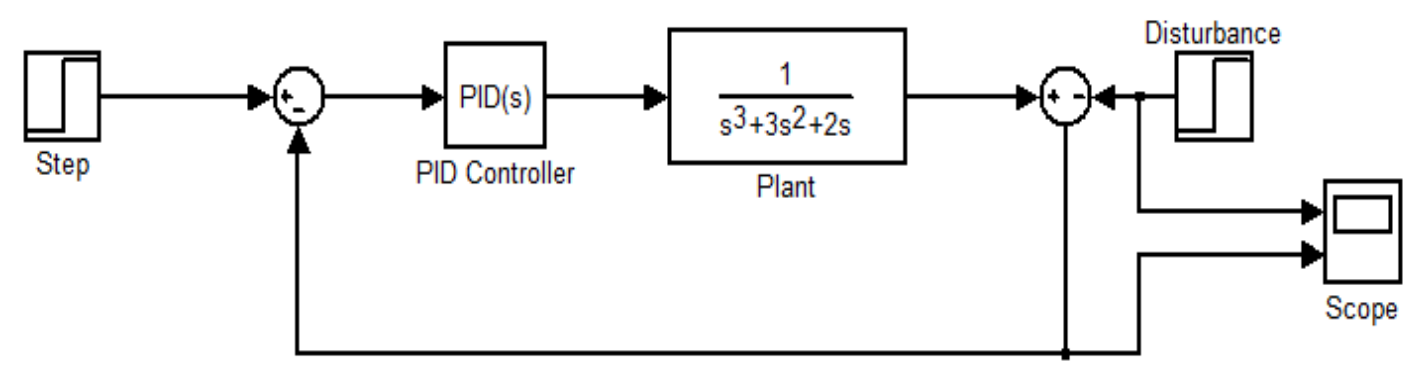

(a)

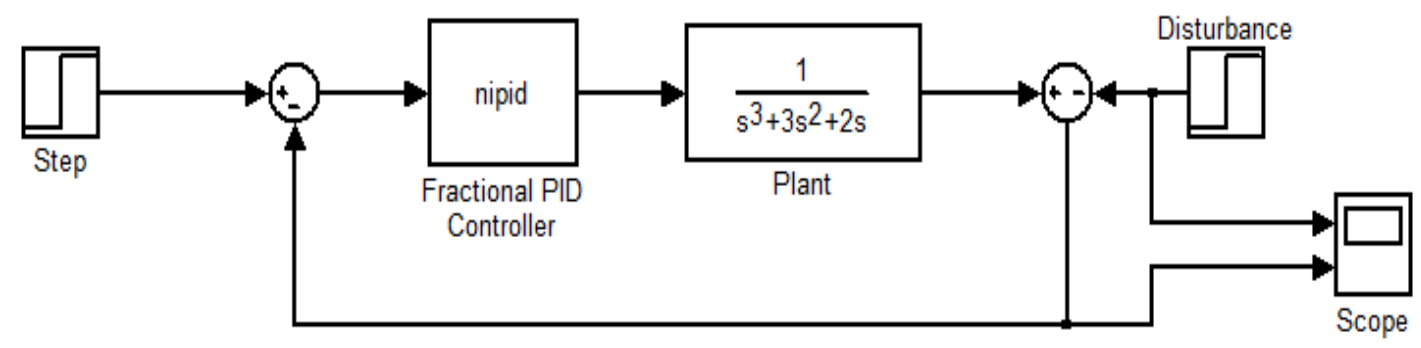

(b)

Figure (6): a- System for PID Controller with Disturbance, b- System for FOPID Controller with Disturbance. 


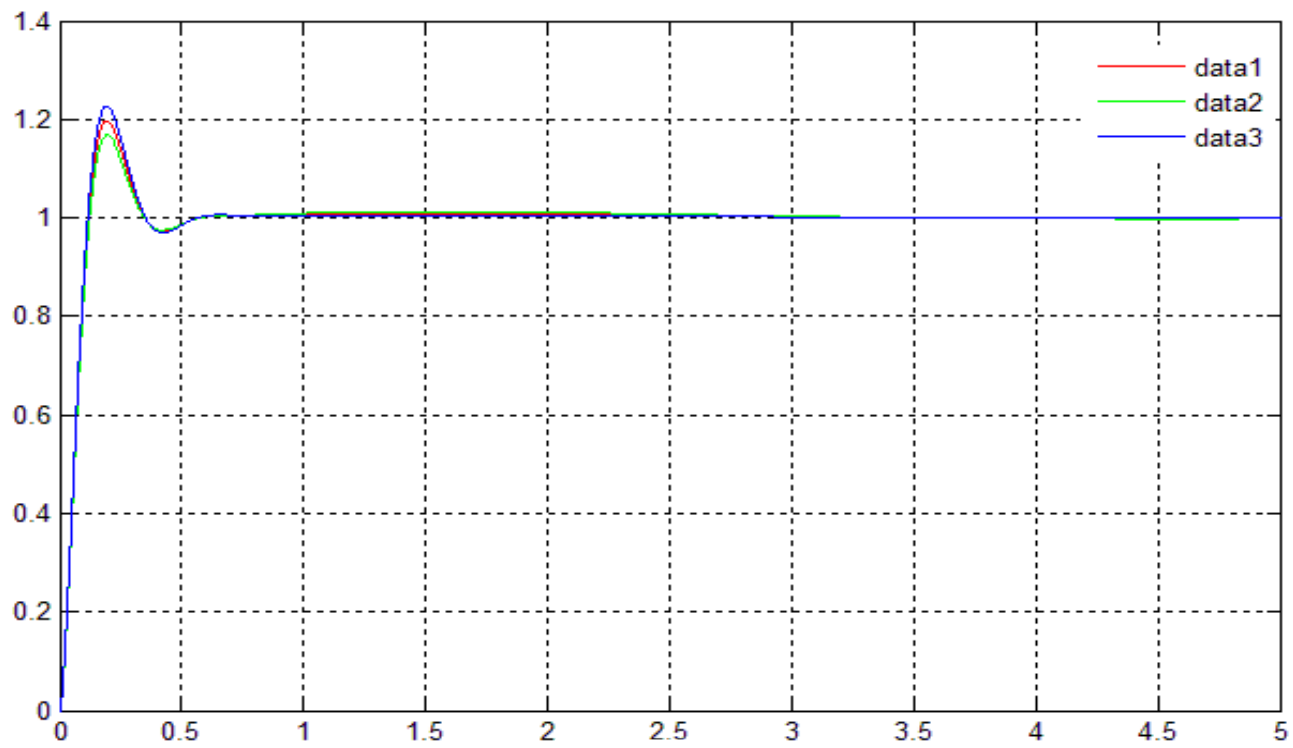

(a)

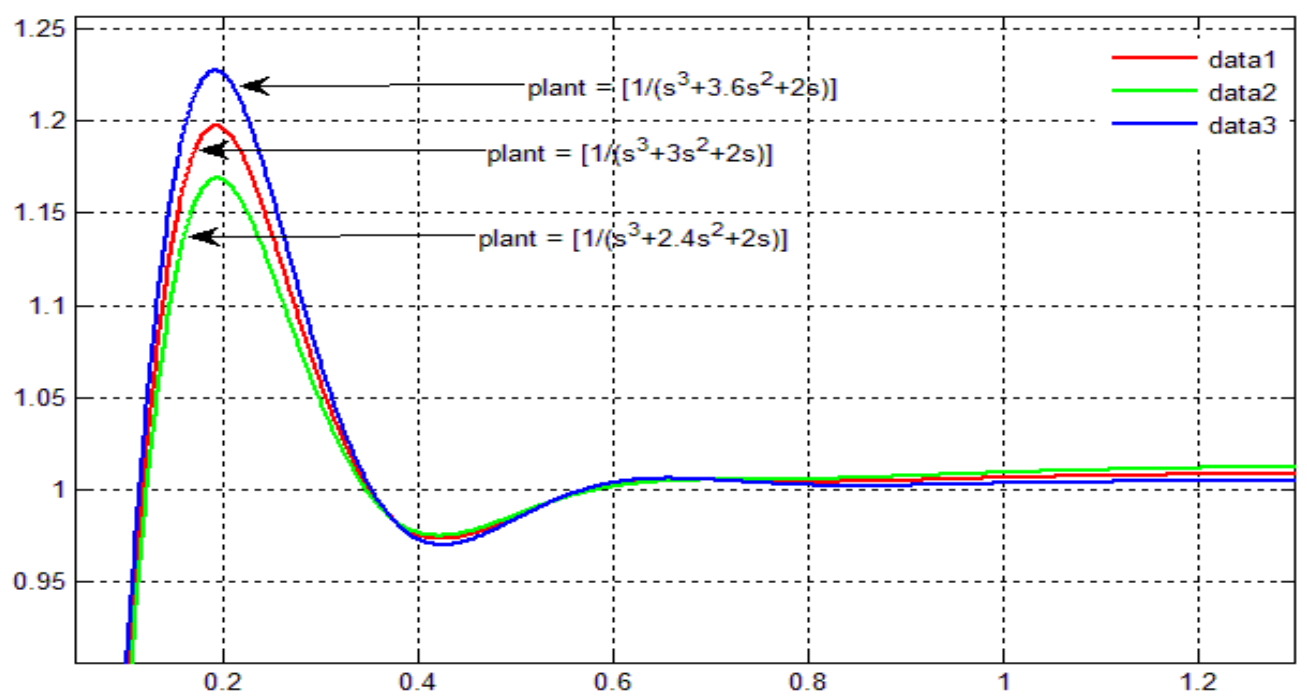

(b)

Figure (7): a-Step Response for System FOPID Controller, b- Focus (zoom) on -a- 


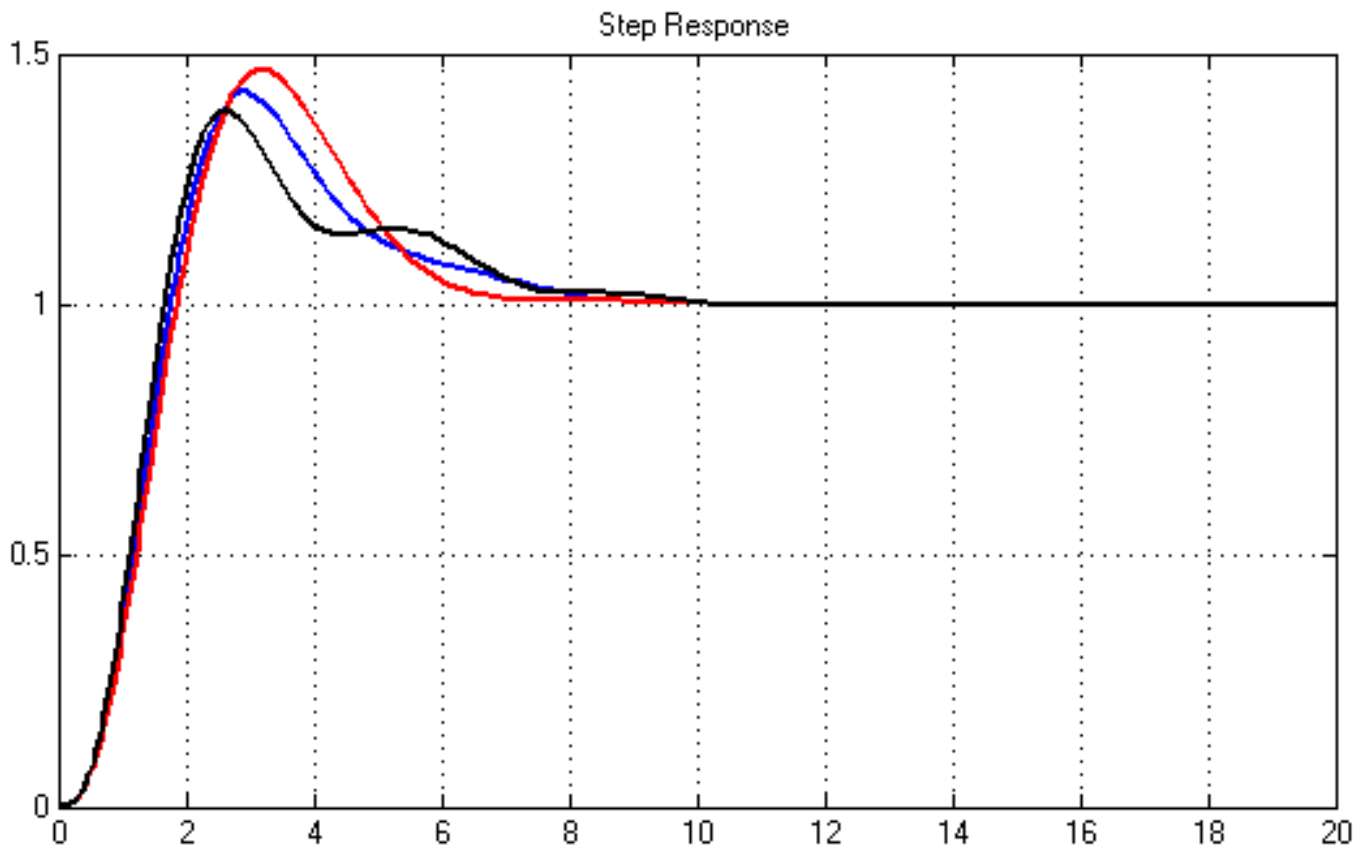

(a)

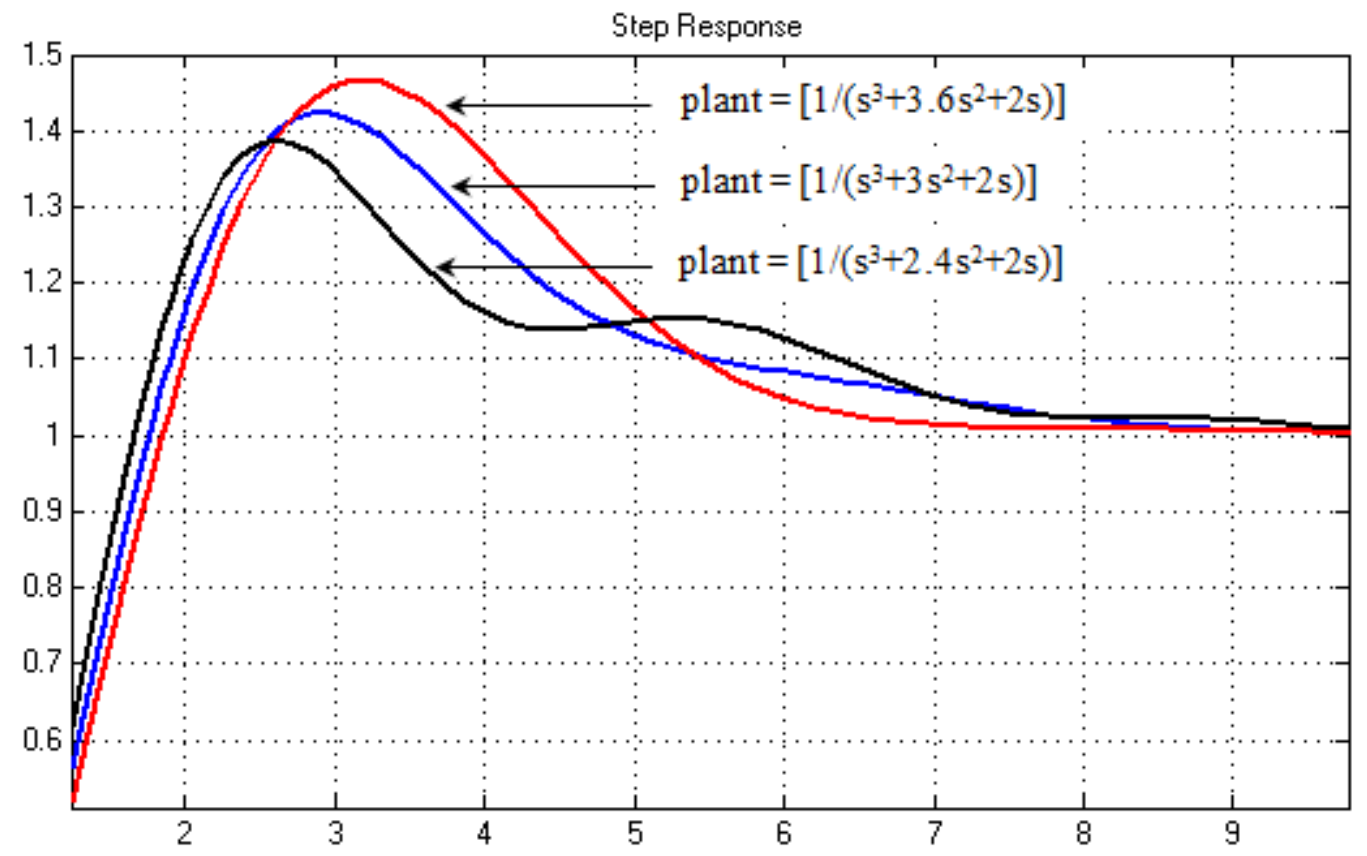

(b)

Figure (8): Step Response for System PID Controller, b- Focus (zoom) on -a- 

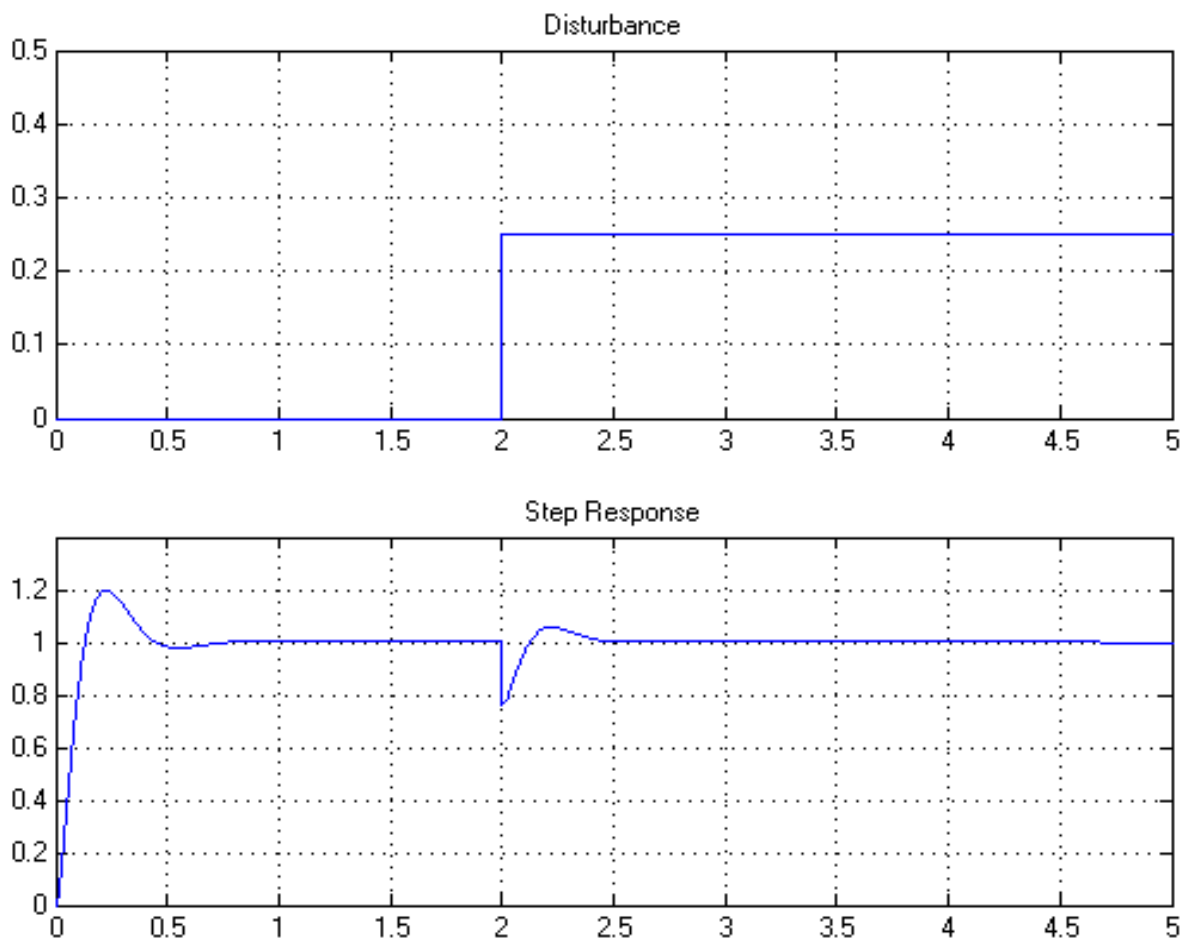

(a)

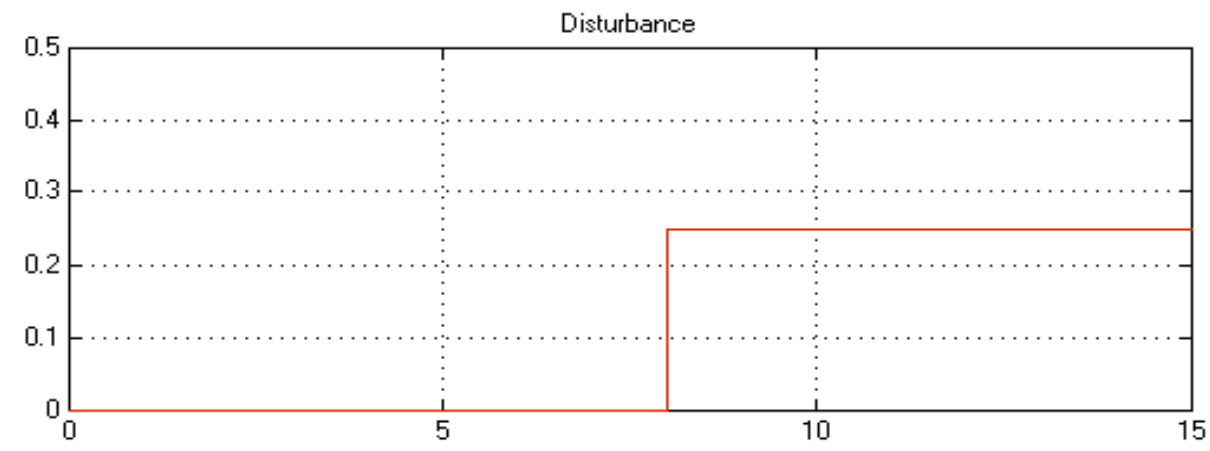

Step Response

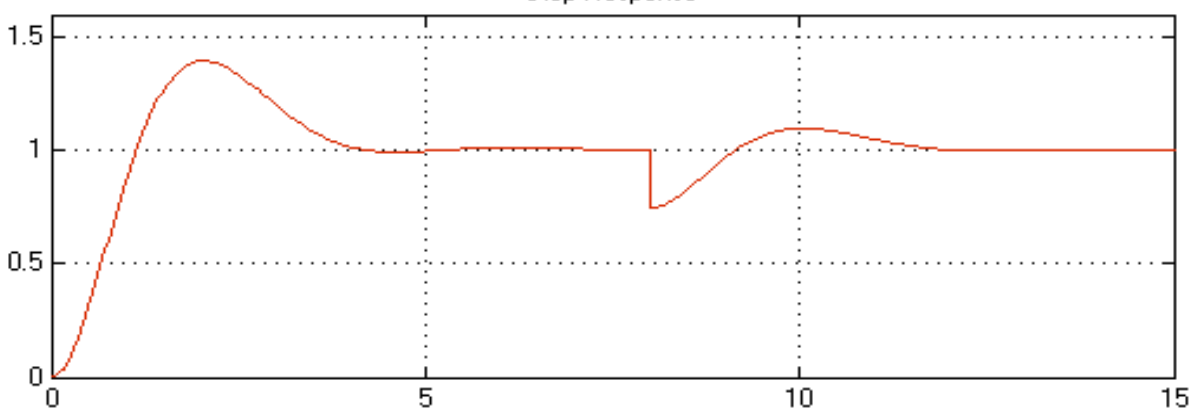

(b)

Figure (9): a- Step Response for System FOPID Controller with Disturbance, b- Step Response for System PID Controller with Disturbance. 


\title{
تصميم المسيطر التناسبي التكاملي التفاضلي الكسري بالاستناد لحشد الجسبمات
}

\author{
عبد الاله خضر محمود 1، بسام فاضل محمد 2

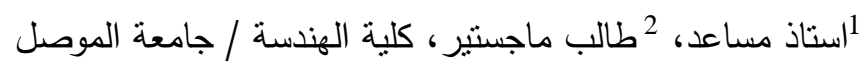

الخلاصة

المسيطر التتاسبي التكاملي التفاضلي الكسري (FOPID controller) يعتبر من نوع المسيطر التتاسبي التكاملي

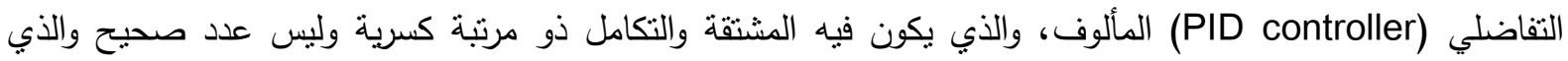
يحتوي على خمسة عوامل للتنغيم.

وفي هذا البحث ينم دراسة هذا المسيطر وطرق التتغيم للحصول على تحسين الاستجابة للمنظومة ذات الحلقة المغلقة بأستخدام المسيطر التتاسبي التكاملي التفاضلي الكسري بالأستعانة بمحاكاة برنامج الماتلاب.

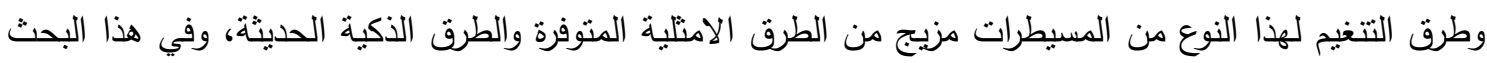
تم اسخدام الطريقة الامنلية لحثد الجسيمات لتصميم المسيطر التناسبي التكاملي التفاضلي الكسري، والذي يتم تحديد عوامل المسيطر باستخدام القيمة الصغرى المثلى لتكامل القيمة المطلقة لزمن اشارة الخطأ (ITAE)، واهم ميزة للبحث ان

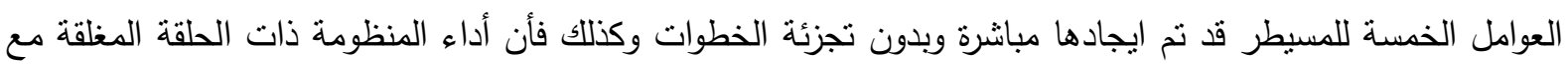
المسيطر الكسري يصبح اكثر تحسنا واكثر متانة بالمقارنة بالمسيطر التقليدي. 